\title{
El quiasmo en el Praeceptum de san Agustín (II)
}

Pío de Luis VizCAÍNO

SUMARIO: En el presente artículo el autor estudia los quiasmos detectados en los capítulos del dos al cuatro del Praeceptum agustiniano.

PALABRAS CLAVE: Quiasmo, paralelismo, figuras retóricas

ABSTRACT: On this article, the author studies the chiasmus found in the chapters two, three an fourth of augustines's Praeceptum.

KEY WORDS: Chiasmus, parallelism, rethoric figures of speech

\section{Capítulo segundo}

También el capítulo segundo está compuesto mediante una estructura quiásmica, pero no incluye ningún otro quiasmo en su interior.

\section{Quiasmo no 5 (par. 10-13)}

(A) Orationibus instate...

(B)... in oratorio nemo aliquid agat nisi ad quod est factum... si eis uacat, orare uoluerint

(B')... hoc versetur in corde quod profertur in uoce

(A') Et nolite cantare nisi quod legitis esse cantandum...

El paralelismo y la posición invertida de los dos miembros de ambas secuencias permite advertir la estructura quiásmica. El paralelismo de los 
miembros exteriores lo fundan dos imperativos en segunda persona del plural (instate $[\mathrm{A}] /$ nolite cantare $\left[\mathrm{A}^{\prime}\right]$ ); el de los miembros interiores, la tercera persona del singular del presente de subjuntivo en uno y otro (agat $[\mathrm{B}]$ versetur [B']).

La estructura quiásmica contrapone especularmente al grupo y al individuo. En efecto, los miembros exteriores contemplan al grupo en cuanto tal (los plurales instate $[\mathrm{A}] /$ nolite cantare $\left[\mathrm{A}^{\prime}\right]$ ), mientras los miembros interiores contemplan a los individuos (los singulares agat $[\mathrm{B}] /$ versetur $\left[\mathrm{B}^{\prime}\right]$ ).

Pero las dos secuencias no sólo contraponen en forma invertida las dos acciones que acabamos de señalar. Contraponen también, en simple paralelismo antitético, las categorías de obligatoriedad y de libertad y las de interioridad y exterioridad. La obligatoriedad y la libertad aparecen expresadas en la primera secuencia: su primer miembro indica la obligatoriedad (el imperativo absoluto instate [A]); el segundo, la libertad (si... orare uoluerint $[\mathrm{B}])$. La interioridad y la exterioridad están expresadas en la segunda secuencia; a la interioridad se refiere su primer miembro: la referencia al corazón (in corde [B']); a la exterioridad, el segundo: el canto (cantare $\left.\left[\mathrm{A}^{\prime}\right]\right)$. Por último, la primera secuencia contempla en general el hecho de orar (instate orationibus [A]/ si orare uoluerint [B]), mientras la segunda lo contempla en el contexto concreto del canto (psalmis et himnis cum oratis ${ }^{1}\left[\mathrm{~B}^{\prime}\right]$ /nolite cantare $\left.\left[\mathrm{A}^{\prime}\right]\right)^{2}$.

Lo dicho puede visualizarse en la siguiente representación:

\begin{tabular}{llll} 
grupo & A xxxxxxxxxx A & \multicolumn{2}{l}{ obligatoriedad } \\
& & & general \\
individuo & B xxxxxxxxxx B & libertad & \\
individuo & B' $x x x x x x x x ~ B '$ & interioridad & \\
& & & concreto \\
grupo & A' $^{\prime}$ xxxxxxxx A' & exterioridad &
\end{tabular}

En este capítulo del Praeceptum el legislador se propone regular la oración monástica, sacando a colación diversos aspectos de la misma. Al

1 Tanto los salmos como los himnos son textos compuestos para ser cantados. Cf. L. VERHEIJEN, Éléments d'un Commentaire de la Règle de saint Augustin. XXI. «Prier Dieu par des psaumes et des «hymnes», en Augustiniana 37 (1987) 5-37.

${ }^{2}$ En el plano literario se constata el homoteluton en los miembros exteriores (instate/nolite) y en el primer miembro de la segunda secuencia (uersetur/profertur), y el paralelismo entre las dos secuencias en el sucederse de una orden y una prohibición (instate -nemo agat/versetur - nolite cantare). 
considerar en su conjunto los cuatro miembros del quiasmo, queda clara la complementariedad de los aspectos comunitario -referencias al grupo- y personal -referencias al individuo- de la oración. El legislador comienza instando a todos (instate, en plural) a asistir a los tiempos de oración, y concluye con el precepto de que no canten sino lo que debe cantarse. El imperativo de segunda persona del plural (nolite cantare) alcanza a los monjes en su conjunto. Pero el legislador no queda satisfecho con el simple promover la oración en común y, en consecuencia, presta también atención al aspecto personal, desde dos perspectivas diferentes. La primera consiste en promover la oración individual del monje, contemplando que pueda dedicarle el tiempo que le quede libre, después de realizar las tareas debidas. Con esa finalidad ordena que nadie haga (nemo ... agat) en el oratorio otra cosa que la indicada en su mismo nombre. El pronombre indefinido nemo le sirve para referirse a cada monje en particular, sin excluir a nadie. La segunda consiste en indicar el modo como cada cual ha de hacer la oración común cuando esta consiste en salmos e himnos: lo que dice con la voz ha de hallar correspondencia en su corazón (uersetur in corde): en el corazón de cada monje, individualmente considerado. El hecho de comenzar el párrafo con el verbo de la oración subordinada en segunda persona del plural (cuando oráis [cum oratis]) hacía esperar que el sujeto de la oración principal fuese la misma segunda persona del plural, pero el legislador ha optado, para formular su precepto, por la tercera persona del presente de subjuntivo en singular (uersetur), y para ello ha cambiado el sujeto de la oración.

Lo primero que el legislador deja claro es la importancia de la oración, ordenando de entrada frecuentarla asiduamente; lo segundo, que la obligación no debe anular la espontaneidad o, dicho diversamente, que la obligatoria oración en común no excluye la oración privada, individual. El imperativo "sed asiduos a las oraciones en las horas y tiempos establecidos" es absoluto, lo que no cabe interpretar sino como condición de obligatoriedad. Pero, al mismo tiempo ve con buenos ojos la oración privada, al ordenar que nadie haga en el oratorio algo que pueda impedirla a quien deseara hacerla en los momentos en que le fuera lícito dedicarse a ella. Más aún, parece ser su opción preferida para el tiempo libre del monje.

Pero la oración puede realizarse de diversas maneras. Son varias las modalidades en su manifestación externa. En la segunda secuencia, el legislador se centra en una de ellas: la oración con canto. Dato doblemente revelador: de una parte, del hecho en sí mismo; de otra, de que el santo, a la vez que la aceptaba, tenía sus reservas. Al respecto, hace hincapié en que la acción exterior no basta, si no va acompañada de la debida actitud inte- 
rior. En consecuencia, señala que lo que se profiere con la voz ha de tener correspondencia en el corazón y, más todavía, ordena que sólo se cante aquella parte de la Escritura que fue compuesta para ser cantada, esto es, los salmos e himnos contenidos en ella. Tras esta orden subyace el temor de que, si el texto sagrado se hace acompañar de la música, el monje se deje arrastrar por la melodía y no se encuentre con Dios en su palabra. Sólo que el temor a que el monje se quede en lo exterior denota el amor al encuentro íntimo, en el corazón, con Dios.

\section{Capítulo tercero}

El conjunto del capítulo tercero del Praeceptum tiene la forma de una estructura concéntrica. Dentro de ella advertimos dos quiasmos más.

\section{Quiasmo no 6 (par. 14-18)}

(A) ... Quando aliquis non potest ieiunare, non tamen extra horam prandii aliquid alimentorum sumat

(B) nisi cum aegrotat

(C) ... nec solae uobis fauces sumant cibum, sed et aures esuriant Dei uerbum .

(A') Qui infirmi sunt ex pristina consuetudine, si aliter tractantur in uictu ... et si eis qui uenerunt ex moribus delicatioribus ad monasterium, aliquid ... alimentorum datur...

(B') ... quemadmodum aegrotantes necesse habent minus accipere ne grauentur... ita et post aegritudinem tractandi sunt, ut citius recreentur...

La estructura concéntrica resulta clara: el legislador dedica el miembro central al alimento espiritual y los cuatro restantes al alimento físico. La particularidad de esta estructura concéntrica, que la distingue de otras del documento monástico agustiniano consiste en que los cuatro miembros referidos al alimento físico están dispuestos en estructura paralela, no en estructura quiásmica (ab/a'b' en vez de ab/b'a').

El paralelismo entre las dos primeras secuencias es de naturaleza conceptual, no gramatical o sintáctica. Tanto sus primeros miembros como los 
segundos se refieren a las mismas personas. Aquellos a los que se les dispensa del ayuno, pero respetando la hora del prandium (aliquis non potest ieiunare, non tamen extra horam prandii aliquid alimentorum sumat [A]) se identifican con los débiles y de costumbre más delicadas que reciben un trato especial en alimentación (infirmi... si aliter tractantur in uictu ... et si eis ... ex moribus delicatioribus... aliquid ... alimentorum datur... [A']). Más claro aparece que sus segundos miembros se refieren a los enfermos (cum aegrotat [B]/aegrotantes [B'])

Así, pues, el texto contrapone, de una parte, el alimento físico al espiritual; de otra, a dos grupos de monjes y al conjunto de los mismos. El alimento espiritual, al que se refiere el miembro central, está escoltado por los otros cuatro miembros, que se refieren, aunque no solo a él, al alimento físico. En relación con este último, contrapone dos grupos (a/a' y b/b') a la totalidad. El grupo (a) contempla a los débiles; el grupo (b), a los enfermos, como ya indicamos. Pero la referencia a estos dos grupos no es idéntica en los dos primeros miembros (A-B) y en los dos últimos (A'-B'). En los primeros el legislador formula el principio más general: los débiles no están obligados al ayuno, pero sí al horario del prandium; los enfermos, ni al ayuno ni al horario; en los dos últimos se refiere ya a los alimentos en concreto: una dieta más delicada (aliter tractantur in uictu... /... datur quod aliis fortioribüs non datur [A']) para los débiles, y aligerar la dieta para los enfermos (necesse habent minus accipere... [B']). El alimento espiritual, en cambio, no está contemplado para ningún grupo específico, sino para todos: sanos, débiles y enfermos.

Lo dicho se puede visualizar en esta presentación:

\begin{tabular}{|c|c|c|c|}
\hline \multirow{2}{*}{ alimento físico } & $A \operatorname{xxxxxxxxxx} A$ & grupo (a) & \multirow{2}{*}{ horario } \\
\hline & B $x x x x x x x x x x B$ & grupo (b) & \\
\hline \multirow[t]{2}{*}{ alimento espiritual } & 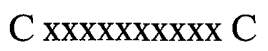 & todos & \\
\hline & 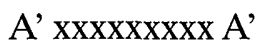 & grupo (a') & \\
\hline & B' $x x x x x x x x x$ B' & grupo (b') & \\
\hline
\end{tabular}

Mediante esta estructura literaria, el legislador pone bien en resalto que todos los monjes necesitan el alimento espiritual. Deja claro también que el hombre ni es solo cuerpo ni es sólo alma, sino un compuesto de alma y cuerpo y que ambos elementos han de ser nutridos de forma adecuada: el alma, con la palabra de Dios de la que ha de sentir hami. :e; el cuerpo, con el horario y la dieta adecuada a su estado de salud. 
Con su texto el legislador deja bien claros dos principios que han de regir el régimen alimentario del monasterio. El primero se centra en el alimento en sí mismo; el segundo, en las personas que lo han de recibir. La referencia al alimento aparece en la columna de la izquierda. El autor parte de que el hombre no es solo cuerpo ni solo espíritu, sino un compuesto de cuerpo y espíritu y que ambos componentes han de recibir su alimento específico: el cuerpo, el físico; el espíritu, el espiritual, esto es, la palabra de Dios. ¿Cuál es más importante? La respuesta la advertimos en la estructura literaria: la ubicación del alimento espiritual en el miembro céntrico sólo cabe interpretarla como lugar de privilegio y, por tanto, como indicadora de su mayor importancia. El alimento físico le hace de doble escolta por un lado y otro.

La referencia a las personas-los monjes-que han de recibir el alimento aparece en las columnas de la derecha. De una parte, todos han de recibir por igual el alimento espiritual; no es tolerancia ni privilegio que se tenga con determinada categoría de monjes. Por supuesto, todos han de recibir también el alimento físico. El dato está presupuesto en el precepto general que abre el capítulo: en principio y en la medida en que la salud lo permita, todos han de someter su carne con ayunos y abstinencia en la comida y la bebida. Pero hay monjes que no pueden cumplir el precepto y que ocupan la atención del legislador: los débiles y los propiamente enfermos. Para unos y para otros reclama un trato especial, en dos ámbitos específicos: en el del horario -no cualquiera, sino específicamente el del prandium o primera comida del día-, y en la dieta. Uno y otro han de adaptarse al específico estado de salud. Es la proclamación del principio del trato individual. En lo referente al alimento espiritual no hay diferencias, pero sí con referencia al alimento físico. Es la proclamación del principio de la atención individualizada.

\section{Quiasmo nº 7 (par. 16)}

Qui infirmi sunt ... si aliter tractantur in uictu

\section{(A) non debet aliis molestum esse nec iniustum uideri}

(B) quos facit alia consuetudo fortiores.

(B') Nec illos feliciores putent, quia sumunt quod non sumunt ipsi (A') sed sibi potius gratulentur, quia ualent quod non ualent illi.

En el texto es fácil advertir dos secuencias paralelas cuyos miembros se encuentran en posición invertida. El paralelismo de los miembros exte- 
riores se funda en verbos que hacen referencia a una actitud psicológica (molestum esse ... iniustum uideri [A]/ (gratulentur [A']); el de los miembros interiores en una referencia a la condición personal, indicada con sendos adjetivos en grado comparativo (fortiores [B]/(feliciores [B']).

La estructura quiásmica contrapone especularmente sentimiento y razón. Los miembros exteriores presentan el sentimiento que, a juicio del legislador, no debe o, respectivamente, debe embargar a los monjes a los que se refiere, formulado primero en negativo y luego en positivo; en negativo: no han de sentir como inaceptable e injusto el proceder seguido en el monasterio (molestum esse ... iniustum uideri [A]); en positivo: han de felicitarse por su buena salud (gratulentur [ $\left.\mathrm{A}^{\prime}\right]$ ). Los miembros interiores justifican lo expuesto en los extremos. Los descontentos no deben sentirse injustamente tratados, porque el régimen que siguen los está haciendo más robustos (fortiores [B]); al contrario, deben alegrarse y no juzgar a los otros más felices, porque personalmente gozan de mejor salud (feliciores quia ualent quod non ualent illi $\left.\left[\mathrm{B}^{\prime}\right]\right)$.

Pero las dos secuencias no sólo contraponen en forma invertida las dos acciones que acabamos de señalar. Contraponen también, en simple paralelismo antitético, subjetividad y objetividad en cada una de ellas. Los primeros miembros de cada secuencia expresan una opinión (uideri $[\mathrm{A}]$ putent [B') -subjetividad-, mientras sus segundos miembros expresan una realidad (facit [B]/ualent [A']) -objetividad-. También contraponen dos cualidades: lo agradable y lo eficaz. Lo agradable es el criterio que orienta la subjetividad de los monjes descontentos; la eficacia es el criterio que orienta la objetividad que presenta el legislador. Por último, reseñamos un tercer paralelismo, puramente gramatical: el sucederse de negación a afirmación en cada una de las secuencias (non debet - facit/nec putent-ualent) ${ }^{3}$.

Todo lo indicado permite visualizarlo la siguiente representación:

$\begin{array}{lllll}\text { sentimiento } & \text { A xxxxxxxxxx A } & \text { subjetividad } & \text { lo agradable } & \text { negación } \\ \text { razón } & \text { B xxxxxxxxxx B } & \text { objetividad } & \text { lo eficaz } & \text { afirmación } \\ \text { razón } & \text { B' xxxxxxxxx B' } & \text { subjetividad } & \text { lo agradable } & \text { negación } \\ \text { sentimiento } & \text { A' } x x x x x x x x^{\prime} A^{\prime} & \text { objetividad } & \text { lo eficaz } & \text { afirmación }\end{array}$

${ }^{3}$ En el plano literario hay que señalar asimismo el homoteleuton que afecta a dos pares de adjetivos: molestum/iniustum; fortiores/feliciores. 
La superposición de las dos estructuras literarias, la quiásmica y la paralela, ha permitido al legislador defender, para mantenerla, la praxis alimentaria que había establecido para el monasterio. Él se enfrenta al estado de ánimo de determinados monjes que cree injustificado. Quiere desterrar la amargura de quienes se sentían víctimas de un trato que juzgaban injusto y conseguir que, en vez de vivir amargados, hasta se feliciten. Realidad posible si se percatan de que su amargura se fundamenta en una percepción distorsionada o incompleta de la realidad. De ahí que haya querido mostrar la auténtica realidad. Los monjes aludidos advertirán que no tienen razón para sentirse postergados con solo constatar que el régimen que siguen, aunque parezca duro, les hace más robustos que los -a su parecer- privilegiados. Desde una perspectiva positiva, advertirán igualmente que tienen válidas razones para felicitarse con solo constatar que gozan de mejor salud que aquellos a los que envidian.

En la vida monástica, igual que en otros ámbitos, la subjetividad ha de ser contrastada con la objetividad. Es obvio que no se puede prescindir de la subjetividad, pero también que no ha de ser el único criterio que regule la vida. Los monjes no han de criticar desde criterios subjetivos (uideri) un régimen alimentario que, objetivamente (facit), se muestra eficaz al hacer más robustos a los que lo siguen; ni han de considerar, desde criterios subjetivos (putent), más felices a los que no ayunan, cuando objetivamente ellos gozan de mejor salud (ualent). Las dos veces precede la subjetividad y sigue la objetividad, como si el legislador quisiera tapar la primera, a su juicio errónea, con la segunda.

A nadie le amarga un dulce, dice el refrán. Pero por distintas y justas razones pueden faltar los dulces. Ante una situación de estas características, el legislador presenta su filosofía: hay que tratar de ver siempre el lado positivo de las situaciones negativas: no hay dulces, pero la salud mejora. En el fondo está el tema de la felicidad con que argumentaban los monjes descontentos. El legislador no se lo reprocha. Iría contra su planteamiento antropológico, que se correspondía con el de toda la filosofía antigua. La felicidad, lejos de estar reñida con la vida monástica, es su aliada cuando se vive conforme a su naturaleza. El problema no está en que la busquen, sino en dónde la buscan. Es imprescindible fundamentarla debidamente. Los monjes descontentos la cifraban en el comer, en no tener que ayunar, en definitiva en el placer físico -lo que les equiparaba a los epicúreos, cuya escuela tenía mala prensa en el cristianismo antiguo-; la prueba es que consideraban más felices (feliciores) a los que no tenían que ayunar. Al pensar así, rebajaban al monje al nivel del simple animal. Lo que hace el legislador es elevarlo a un nivel propiamente humano al considerar integrante 
de su felicidad el poder vivir conforme al proyecto libremente elegido. De ahí la importancia dada al ser más robustos y estar en condiciones de llevar con naturalidad el régimen de vida por el que habían optado: en el caso concreto, el monástico que incluía la ascesis alimentaria. Lo agradable no debe ser el único criterio; por encima de él está el de la utilidad y eficacia en relación con el objetivo que uno se ha propuesto.

El quiasmo ha llevado al legislador a poner en paralelo dos comparativos: más robustos (fortiores) y más felices (feliciores). Literariamente se puede hablar de yuxtaposición, conceptualmente de sustitución; el segundo valor queda absorbido por el primero: ese mayor vigor ha de hacer, en el caso concreto, a los monjes más felices.

\section{Quiasmo no 8 (par. 17)}

\section{(A) Nec debent uelle}

(B) omnes

(B') quod paucos

(A') uident amplius [non quia honorantur, sed quia tolerantur] accipere.

Aunque puede no percibirse a primera vista, el texto está construido en forma de quiasmo al contener dos secuencias paralelas cuyos miembros se encuentran en disposición especular. El paralelismo de los miembros exteriores lo manifiesta un dato gramatical: en cada uno de ellos aparecen dos verbos, uno en tiempo personal y otro en infinitivo (debent uelle [A]/ uident... accipere [A']). El paralelismo de los miembros interiores lo fundan dos adjetivos que expresan la categoría cantidad (omnes [B]/paucos [B']).

La estructura quiásmica contrapone especularmente los sujetos de una acción y el número de los mismos. Los miembros exteriores se refieren a unos mismos sujetos (debent uelle [A]/uident ... accipere [A']) y los miembros interiores a su número: la totalidad (omnes [B]) y unos pocos (paucos [B']) ${ }^{4}$.

Lo dicho se puede visualizar en la siguiente presentación:

$\begin{array}{lll}\text { sujetos } & \text { A xxxxxxxxxx A } & \text { deseo } \\ \text { número } & \text { B xxxxxxxxxx B } & \text { totalidad } \\ \text { número } & \text { B'xxxxxxxx B' }^{\prime} \text { parte } \\ \text { sujetos } & \text { A' }^{\prime} x x x x x x x x A^{\prime} & \text { realidad }\end{array}$

\footnotetext{
${ }^{4}$ En el plano literario señalamos el homoteleuton (debent/vident).
} 
El legislador constata que en la comunidad monástica a la que dirige el Praeceptum hay unos monjes -una minoría, los "débiles"- que reciben un trato especial en alimento, vestido y ajuar de cama; constata asimismo que hay otros -la mayoría, "más fuertes"-que suspiran por disfrutar ese mismo trato especial. La mayoría envidia a la minoría y quiere participar de lo que considera que es un privilegio.

Ante esta situación el legislador falla que "no deben desear todos lo que ven que reciben unos pocos". Con otras palabras, que el "deber" no lo debe dictar el "ver"; los sentidos no son criterio válido o, al menos, suficiente para orientar los deseos. Pero el texto dice todavía más: tampoco la estadística ha de ser criterio válido o, al menos, suficiente para orientarlos; los derechos de unos no fundan, sin más, derechos para otros. Este parece haber sido el presupuesto de las reclamaciones del grupo mayoritario de monjes. Para el legislador, el que unos pocos recibieran legítimamente un trato especial no legitimaba que los demás reclamaran el mismo trato, porque no se fundaba en lo que son -al respecto la igualdad, al ser absoluta, reclamaría un trato idéntico- sino en algo que unos poseían y otros no, o unos poseían en mayor grado que otros; en el caso concreto, la salud. Cuando un derecho se funda en una necesidad, quien carece de esa necesidad no puede reclamar ese derecho. La comunidad se asienta sobre la unidad de almas y corazones in Deum, obra del amor, no sobre la uniformidad en el trato. Siempre que la rotura de la uniformidad sea ejercicio de tolerancia con un determinado estado físico, no privilegio fundado en categorías sociales, como pensaban los monjes descontentos que era el caso. Estos gozaban de buena salud física, pero no de salud moral, al no aceptar ese ejercicio de caridad. En ellos el egoísmo prevalecía sobre la tolerancia y quizá hasta sobre la verdad, en el caso de que fuera el ansia de ese trato especial lo que les condujo al engaño. De esta manera podían ver cuán lejos se hallaban del anima una y del cor unum.

La imbricación de los distintos quiasmos se puede ver en esta disposición gráfica:

(A) ... Quando aliquis non potest ieiunare, non tamen extra horam prandii aliquid alimentorum sumat

(B) nisi cum aegrotat

(C) ... nec solae uobis fauces sumant cibum, sed et aures esuriant Dei uerbum.

(A') Qui infirmi sunt ex pristina consuetudine, si aliter tractantur in uictu ... 
(a) ... non debet aliis molestum esse nec iniustum uideri

(b) quos facit alia consuetudo fortiores.

(b') Nec illos feliciores putent, quia sumunt quod non sumunt ipsi

(a') sed sibi potius gratulentur, quia ualent quod non ualent illi.

et si eis qui uenerunt ex moribus delicatioribus ad monasterium, aliquid ... alimentorum datur...

(a) Nec debent uelle

(b) omnes

(b') quod paucos

(a') uident amplius [non quia honorantur, sed quia tolerantur] accipere.

(B') ... quemadmodum aegrotantes necesse habent minus accipere ne grauentur... ita et post aegritudinem tractandi sunt, ut citius recreentur...

\section{Capítulo cuarto}

El capítulo cuarto es el más extenso del Praeceptum, del que ocupa casi una cuarta parte. Es lógico, pues, que en él se encuentren más quiasmos o estructuras quiásmicas que en cualquier otro. Sin embargo, a diferencia de los anteriores, no podemos afirmar que todo él esté estructurado en forma de quiasmo, aunque sí una buena parte del mismo.

\section{Quiasmo n⿳9 (par. 22)}

(A) Neque enim quando proceditis feminas uidere prohibemini, sed appetere,

(B) aut ab ipsis appeti velle, criminosum est.

(B') Nec solo tactu ... sed adspectu quoque appetitur (concupiscentia feminarum)

(A') et appetit concupiscentia feminarum... 
El paralelismo y la posición invertida de los dos miembros de ambas secuencias deja claro que estamos ante una estructura quiásmica. El paralelismo tanto de los miembros exteriores como de los interiores lo funda el verbo appeto, presente en todos ellos en dos formas gramaticales: infinitivo y tiempo personal. En los miembros exteriores aparece en voz activa (appetere $[\mathrm{A}] /$ y appetit [A']) en los miembros medios, en voz pasiva (appeti $[\mathrm{B}] /$ y appetitur [B']).

La estructura quiásmica contrapone especularmente una acción y una pasión en relación con la castidad. Los miembros externos contienen la acción y los interiores la pasión. La acción -verbo en activa- se ubica en los miembros exteriores: desear mujeres (feminas... appetere [A]), y el desear de la concupiscencia (appetit concupiscentia [A']); la pasión -verbo en pasiva-en los miembros interiores: ser deseado (appeti [B]) y es deseada (appetitur [B']).

Pero las dos secuencias no sólo contraponen en forma invertida las dos categorías señaladas. Contraponen también, en simple paralelismo, al monje que desea y es deseado y a la concupiscentia feminarum que igualmente es deseada y desea. En efecto, la primera secuencia contempla, en su primer miembro, al monje como sujeto activo del deseo cuyo objeto son las mujeres (feminas appetere [A]) y en el segundo, al monje como sujeto pasivo con las mujeres como complemento agente (ab ipsis appeti [B]); a su vez, la segunda secuencia contempla, en su primer miembro, la concupiscentia feminarum como sujeto pasivo y -sobreentendido- el monje como complemento agente (appetitur concupiscentia [feminarum] [B']), y en el segundo, a la misma concupiscentia como sujeto activo cuyo objeto -igualmente sobreentendido- es el monje (appetit concupiscentia feminarum [A']). Así, pues, tanto la acción como la pasión tienen un doble sujeto, el monje en la primera secuencia y la concupiscentia feminarum en la segunda, y un doble objeto, la mujer en la primera y la concupiscentia feminarum en la segunda ${ }^{5}$.

Lo dicho se puede visualizar mediante la siguiente representación:

\begin{tabular}{|c|c|c|}
\hline acción & A xxxxxxxxxx A & monje \\
\hline pasión & 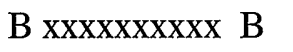 & \\
\hline pasión & B' $^{\prime} x x x x x x x x x x B^{\prime}$ & \\
\hline acción & 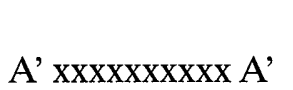 & concupiscentia feminarum \\
\hline
\end{tabular}

5 Otras figuras retóricas presentes son: la anáfora (neque/nec), el homoteleuton (uidere/appetere) y el poliptoton (appetere/appeti/appetitur/appetit). 
En el texto el legislador ha expresado con claridad que el peligro para la castidad puede llegarle al monje de su propio interior o del exterior. Esto significa que el desear a una mujer no requiere necesariamente provocación por parte de ella, aunque existe siempre como posibilidad, y que dentro de sí mismo tiene la fuente de la que pueden manar los vapores tartáreos de la lujuria ${ }^{6}$. Si unas veces es la mirada lujuriosa ajena la que suscita el deseo también lujurioso, otras veces es el deseo lujurioso el que da curso al mirar con lujuria a una mujer. Sabiendo siempre que la provocación ajena hay que considerarla más como ocasión que como causa, puesto que no tendrá consecuencias si no encuentra respuesta positiva en la persona provocada. No basta, pues, una prevención exterior; se requiere también la prevención interior.

El legislador parte de que, al respecto, no hay diferencia entre el hombre y la mujer. Lo que refiere primero del hombre respecto de la mujer, luego lo afirma de la mujer respecto del hombre. Tanto uno como la otra pueden ser sujetos y objetos de concupiscencia en relación con la otra persona del sexo opuesto.

El texto expresa otras ideas. Una de ellas tiene que ver con la moralidad. El legislador tacha de gravemente inmoral (criminosum) tanto el deseo "activo" como el "pasivo", el desear como el querer ser deseado; en cambio, el simple ver, pura actividad del sentido de la vista, lo juzga moralmente inocuo. Cierto que este juicio moral sólo aparece en la secuencia relativa al monje, no en la referida a la mujer. Pero no hay que atribuir particular valor a ese silencio, porque, al tratarse del mismo deseo lujurioso, emitido el juicio en la primera secuencia, ya no tenía necesidad de repetirlo en la segunda. Significativo puede ser que, de modo paralelo, en la segunda secuencia el santo no atribuya el deseo pecaminoso directamente a las mujeres, sino a la concupiscentia presente en ellas, dejando entender que lo mismo vale para el monje, estando dicha concupiscentia en la fuente del negativo juicio moral. El legislador distingue problemas pero las respuestas valen indistintamente. El juicio moral respecto del recíproco deseo lujurioso lo trata en relación con el monje; el del origen del mismo, la concupiscentia, en relación con la mujer. Y como el juicio moral hecho en relación con el monje vale también para el deseo de la mujer, de igual modo el origen del mismo, la concupiscentia, expresado en relación con la mujer, se aplica también al monje.

En este contexto conviene señalar que, partiendo de este capítulo cuarto, no cabe la acusación de misoginia vertida contra su autor. La estructura quiásmica deja el debate sobre la responsabilidad moral en tablas:

${ }^{6}$ Cf. Conf. $3,1,1$. 
si ciertamente el legislador tiene en cuenta que la mujer puede buscar "seducir" al monje, también tiene en cuenta el caso contrario: que el monje busque "seducir" a la mujer. Si la mujer se mueve para que el monje la desee, también se mueve el monje para que lo desee la mujer, o se complace en ser deseado por ella. El texto, es cierto, contempla que la mujer pueda representar un peligro para el monje, pero antes ha contemplado que el monje puede representarlo para la mujer. La mujer puede presentarse como un objeto de deseo que cautive la mirada lujuriosa del monje, pero el monje puede deleitarse en ser igualmente objeto de la mirada lujuriosa de una mujer.

El legislador parte siempre del monje, ya sea en cuanto desea a la mujer, ya sea en cuanto que le agrada ser deseado por ella; sólo en un segundo momento contempla que la mujer es deseada o que ella desee. Del quiasmo no se puede concluir que el peligro para el monje venga ni sólo ni primero de la mujer; más bien, habría que concluir lo contrario, que el peligro llega antes del monje a la mujer, ya en la mirada, ya en el deseo. Más bien parecería que la mirada o el deseo de la mujer es consecuencia de la respuesta a la mirada o deseo del monje.

\section{Quiasmo no 10 (par. 22-29)}

\section{(A) Nec solo tactu et affectu,}

(B) sed aspectu quoque appetitur et appetit concupiscentia feminarum...

(B') si hanc de qua loquor oculi petulantiam...

(A') etiam in ceteris inueniendis...peccatis...

El presente quiasmo organiza buena parte del capítulo cuarto del Praeceptum. Del amplio texto sólo hemos trascrito los elementos necesarios para que sea perceptible.

El paralelismo y la posición invertida de los dos miembros de ambas secuencias deja claro que estamos ante una estructura quiásmica. El paralelismo de los miembros exteriores no es fácil de detectar, pues lo esconde el pronombre indefinido ceteris. En efecto, el primero de ellos habla del tacto y el afecto (tactu et affectu [A]); el segundo habla de otros pecados (ceteris... peccatis [ $\left.\left.\mathrm{A}^{\prime}\right]\right)$, tomando como referencia al tacto y al afecto. El paralelismo de los miembros interiores lo funda la presencia del sentido de la vista en uno y otro: la mirada (adspectu [B]) y la oculi petulantiam [B']. 
La estructura quiásmica contrapone especularmente dos cauces de que se sirve la lujuria. El primero (a) es el sentido del tacto y el afecto, el segundo (b) el sentido de la vista. En efecto, los miembros exteriores se ocupan del primero: el primero menciona explícitamente el tacto y el afecto (tactu et affectu [A]); el segundo, los oculta bajo el indefinido "los restantes" (ceteris [A']), con referencia a ellos; los miembros interiores se refieren ambos al sentido de la vista; uno habla de la mirada (adspectu [B]) y el otro de la oculi petulantiam [B'].

Pero las dos secuencias no sólo contraponen en forma invertida las dos acciones que acabamos de señalar. Contraponen también, en simple paralelismo, fuentes del deseo lujurioso y sus manifestaciones pecaminosas. La primera contempla dos fuentes: primero el tacto y el afecto (tactu et affectu [A]) y luego la mirada (adspectu [B]); la segunda, dos manifestaciones pecaminosas: primero, el pecado que tiene lugar mediante el sentido de la vista (oculi petulantiam [B']) y luego los otros pecados (ceteris... peccatis $\left.\left[\mathrm{A}^{\prime}\right]\right)$, sin duda en relación con el tacto y el afecto ${ }^{7}$.

Lo dicho se puede visualizar en esta presentación:

$\begin{array}{llr}\text { cauce (a) } & \text { A } x x x x x x x x x \text { A } & \text { fuente } \\ \text { cauce (b) } & \text { B xxxxxxxxxx B } & \text { pecados/vista } \\ \text { cauce (b') } & \text { B' } x x x x x x x x \text { B' } & \text { manifestación pecaminosa } \\ \text { cauce (a') } & \text { A' } x x x x x x x x \text { A' } & \text { otros pecados }\end{array}$

En este quiasmo, acabamos de decir, el legislador presenta el deseo lujurioso en sus fuentes y en sus manifestaciones en forma de pecado. Con ambos aspectos relaciona de un lado el tacto y el afecto, es decir, un sentido corporal y una manifestación de la voluntad; de otro, el sentido de la vista.

La importancia que el legislador otorga al sentido de la vista en relación con la lujuria se puede deducir de lo desproporcionado en extensión del texto dedicado al sentido de la vista, comparado con el dedicado al tacto y al afecto en ambas secuencias. Importancia que él consideró oportuno resaltar porque, al parecer, no era reconocida. De hecho, la frase "no sólo

${ }^{7}$ De hecho, los ejemplos que pone hay que considerarlos como expresión pecaminosa de afecto: recibir ocultamente cartas o regalos (ut occulte ab aliqua litteras uel quaelibet munuscula accipiat [praec. 4,29]). 
(nec solo) con el tacto y el afecto, sino también (sed... quoque) con la mirada", deja entender que, a juicio del legislador, a los destinatarios del código monástico les parecería obvio que el tacto y el afecto encendiesen el deseo lujurioso, pero no la mirada. El mismo hecho de que, más adelante, tenga que defender con uñas y dientes el procedimiento que propone para curar el mal de la lujuria que se manifiesta en la mirada lujuriosa prueba que los destinatarios del texto no lo consideraban aceptable, quizá porque no daban suficiente importancia al sentido de la vista en ese ámbito.

Entonces ¿por qué reserva al tacto y al afecto y no a la mirada los miembros exteriores del quiasmo? Apuntamos una posible respuesta, tomada del mismo texto: la relación entre comienzo, representado por el pecado cometido con la mirada ${ }^{8}$, y desarrollo, representado por el acto y el afecto ${ }^{9}$. La mirada es peligrosa porque puede abrir las puertas al deseo y acción lujuriosos, razón por la que hay que tenerla bajo control; pero más peligroso es el tacto y el afecto, en cuanto representan un grado más en una escalada de cesión a la lujuria. Y precisamente la mayor gravedad de las manifestaciones pecaminosas vinculadas al tacto y al afecto es un argumento más para cortar de inmediato el mal en el nivel incipiente de la mirada. La presente estructura quiásmica, pues, se encuadra en el proceder habitual del legislador que se caracteriza por ubicar en los términos exteriores lo que considera de más importancia, en este caso, el tacto y el afecto respecto a la mirada.

\section{Quiasmo n' 110 (par. 22)}

(A) Nec dicatis uos habere animos pudicos

(B) si habetis oculos impudicos

(B') quia impudicus oculus

(A') impudici cordis est nuntius.

El presente texto, ofrece una nueva reflexión del legislador sobre el tema de la castidad, tras haberlo centrado antes en la cuestión del deseo.

8 "Et si hanc de qua loquor oculi petulantiam... aduerteritis, statim admonete, ne coepta progrediatur" (praec. 4,25).

9 "Quicumque autem in tantum progressus fuerit malum..." (praec.4,29). En este parágrafo especifica algunos de los restantes pecados mencionados en el anterior (ceteris ... peccatis). Restantes con relación a la mirada lujuriosa, cuyos ejemplos, como indicamos en nota precedente, están relacionados con el ámbito afectivo. 
Se trata de un quiasmo simple cuyos elementos, idénticos en ambos casos -sustantivo y adjetivo-, aparecen en posición invertida. El paralelismo de los miembros exteriores lo funda la presencia, en el primero (A), del sustantivo animos y del adjetivo pudicos, y la presencia en el segundo ( $\left.\mathrm{A}^{\prime}\right)$, del sustantivo cordis, sinónimo de animos, y del adjetivo impudici, contrario de pudicos. El paralelismo de los miembros interiores lo funda la presencia, tanto en B como en B', del sustantivo oculus y del adjetivo impudicus, con la diferencia de que en la primera secuencia uno y otro están en plural, y en la segunda en singular. Los sustantivos animos y cordis no solo tienen el valor gramatical de ser sinónimos, sino el lingüístico de proceder de dos distintos ámbitos culturales: el clásico (animos) y el bíblico (cordis).

El quiasmo contrapone en posición invertida la interioridad y la exterioridad. Los miembros exteriores expresan la interioridad mediante dos sustantivos: "almas" (animos [A]), y "corazón" (cordis [A']); los miembros interiores expresan la exterioridad con el sustantivo "ojo", en plural (ocu los [B]), y en singular (oculus [B']). Y siempre en relación con la impureza, mencionada en los cuatro miembros. Aunque literalmente en el primero se hable de "almas puras", el prefijo negativo que falta al adjetivo ( $p u d i$ $\cos$, en vez de im-pudicos) lo suple la negación que afecta al verbo (nec dicatis).

Pero las dos secuencias no sólo contraponen en forma invertida las dos acciones que acabamos de señalar. Contraponen también, en simple paralelismo, el hecho y la explicación del mismo. En efecto, en la primera secuencia el legislador afirma hechos: la existencia de almas y ojos impuros (animos pudicos[A] oculos impudicos [B]): en la segunda da la explicación de lo afirmado: el ojo impuro es consecuencia del corazón impuro (impudicus oculus [B'] impudici cordis est nuntius [A']); así mismo, como el lector ha podido advertir, en la primera se sirve del plural (animos pudicos [A]/oculos impudicos [B]) y en la segunda del singular (impudicus oculus [B'] - impudici cordis [A']) ${ }^{10}$.

Lo dicho puede visualizarse en esta representación:

$\begin{array}{lll}\text { interioridad } & \text { A xxxxxxxxxx A } & \\ & & \text { B } x \operatorname{xxx} \cdot \text { hecho plural }\end{array}$

10 Siempre en el ámbito literario hay que señalar algunas figuras: el homoteleuton (oculus/nuntius) y el doble poliptoton (oculos/oculus; impudicos/impudicus). 


$\begin{array}{lll}\text { exterioridad } & \text { B' } x x x x x x x x x & \\ \text { interioridad } & \text { A' } x x x x x x x x x & \text { A' }\end{array}$

Lo primero que cabe señalar es el curso seguido por el legislador en el capítulo cuarto del Praeceptum en relación con la lujuria: de la mirada ${ }^{11}$, al deseo ${ }^{12}$, y del deseo, al corazón ${ }^{13}$. O lo que es lo mismo: de la manifestación exterior, a la causa, y de la causa, al "lugar" de procedencia. En el medio está el deseo que se manifiesta en la exterioridad, pero que procede de la interioridad, del corazón.

El quiasmo ha servido al legislador para fijar la estrecha relación existente entre la interioridad y la exterioridad de la persona, aplicadas aquí al caso concreto de la lujuria. La interioridad es reconocida como un valor; primero en la palabra de los monjes -presumen de tener almas (animos) puras, limpias-, luego en la mente del legislador -la importancia de tener el corazón (cordis) puro, limpio-. La exterioridad aparece, en cambio, como objeción: si los ojos -realidad exterior- están manchados, también están manchadas las almas -realidad interior-; de igual manera si el ojo-realidad exterior- está manchado, también lo está el corazón -elemento interior-. En definitiva, no se puede presumir de pureza interior si esta no se manifiesta en el exterior.

Todo está al servicio de esa enseñanza. De entrada, el legislador deja entender que los monjes presumen de tener sus almas limpias de toda lujuria, algo que -juzga él- no pueden sostener, si sus ojos estén manchados por el vicio; luego da razón de lo afirmado, presentando los ojos como publicistas de lo que pasa en el corazón: un ojo impuro revela un corazón impuro. Pero mientras la primera afirmación pende de una condicional -: si alguien tiene ojos impuros, no puede pretender tener el ama pura-, la razón dada aparece en términos absolutos -: el ojo impuro es mensajero de un corazón impuro-. El legislador no se pone como objetivo presentar el estado moral de los monjes; se limita a contemplar una posibilidad; no pretende juzgarlos, sino ponerlos sobre aviso. El hecho de que en la primera secuencia utilice en plural verbo y sustantivos ("tenéis almas/tenéis ojos") y en la segunda el singular de uno y otro ("el ojo es mensajero del cora-

11 "In incessu, in statu, in omnibus motibus uestris nihil fiat quod cuiusquam ofendat aspectum... Oculi vestri, et si iaciuntur in aliquam feminarum, figantur in nemine..".

${ }^{12} \mathrm{Cf}$. el quiasmo anterior: appetere/appeti.

13 Presente quiasmo. 
zón") halla su explicación en el hecho de que la realidad concreta admite formas plurales mientras que el principio que la explica es único.

El texto parece presuponer en los monjes un exceso de confianza en el valor asignado a la interioridad. Como si dijeran: "con tal de tener el interior limpio, lo que acontezca en el exterior carece de importancia". ¿Quizá como consecuencia de la insistencia del santo en ese valor? En este supuesto, el legislador reafirma la primacía de la interioridad -no en vano la ubica en los miembros exteriores del quiasmo-, pero asignando también un valor a lo que se manifiesta en el exterior, aunque no de causa, sino de simple revelación. El texto permite ir todavía más lejos: al cambiar el término "alma" del primer miembro exterior por el de "corazón" en el último, hace saber que su opción por la interioridad no es puramente personal, ni se funda en planteamientos filosóficos -animus es un término del lenguaje filosófico agustiniano- sino que es sencillamente bíblico -cor[dis] es un neto concepto bíblico-. Detrás de la afirmación de que el ojo impuro es mensajero del corazón impuro es fácil percibir una referencia a Mt 15,19 donde Jesús enseña que del corazón salen todos los malos pensamientos y deseos. El argumento último, el de más valor, es siempre el que se fundamenta en la Escritura.

De la consideración conjunta del presente quiasmo y del anterior resulta otra idea referente al tema de la castidad: hay que contemplar tanto la dimensión exterior como la interior. Es lo que ha hecho el legislador. La dimensión exterior está vinculada al sentido de la vista; la interior, al deseo y al corazón. La mirada está al servicio de la lujuria, pero esta radica fundamentalmente en el deseo del corazón. La mirada sin deseo lujurioso es inocente; con deseo, es culpable (criminosum), sin que haya distinción entre desear a una persona del sexo opuesto o querer ser deseado por ella. La relación entre la mirada y el deseo no es siempre la misma: unas veces, es la mirada la que enciende el deseo, otras el deseo la que estimula la mirada.

\section{Quiasmo no 12 (par. 23)}

(A) Nec putare debet qui in feminam figit oculum... ab aliis non uideri, cum hoc facit; uidetur omnino et a quibus se uideri non arbitratur.

(B) Sed ecce lateat et a nemine hominum uideatur,

(B') quid faciet de illo desuper inspectore quem latere nihil potest?

( $\left.\mathrm{A}^{\prime}\right)$ An ideo putandus est non uidere, quia tanto videt patientius, quanto sapientius? 
El presente quiasmo estructura el texto del parágrafo quinto del capítulo cuarto. El paralelismo y la posición invertida de los dos miembros de ambas secuencias deja claro que estamos ante una estructura quiásmica. El paralelismo de los miembros exteriores se percibe fácilmente por la presencia en ambos de los verbos putare y videre (putare /uidetur/uideri [A] / putandus/uidere/uidet [A']), y el de los miembros interiores por la presencia en ambos del verbo latere (lateat [B]/latere [B']).

La estructura quiásmica contrapone especularmente conocimiento y ocultamiento de una posible doble acción del monje: clavar los ojos en una mujer y deleitarse si ella clava los suyos en él. Del conocimiento hablan los miembros exteriores; en el primero directamente: el monje piensa que no es visto, pero es visto (nec putare debet ... ab aliis non uideri..., uidetur[A]); en el segundo, mediante una pregunta retórica: “¿O ha de pensarse que no es visto...?" (an putandus est non uideri...?[A']). A su ocultamiento hacen referencia los miembros interiores; en el primero se contempla la posibilidad de que quede oculto (sed ecce lateat...[B]); en el segundo se afirma que a Dios nada queda oculto (quem latere nihil potest [B']).

Pero las dos secuencias no sólo contraponen en forma invertida las dos acciones que acabamos de señalar. Contraponen también, en simple paralelismo, la capacidad cognoscitiva humana al respecto y la capacidad divina. De la capacidad humana se ocupa la primera secuencia afirmándola (uidetur a quibus non arbitratur [A]) o dejándola en suspenso (sed ecce a nemine hominum uideatur [B]); de la capacidad divina trata la segunda afirmando que no se le puede ocultar el hecho (latere nihil potest [B']) y reafirmándola (tanto uidet patientius... [A']). Además, en relación con el monje el legislador habla en términos de subjetividad: él piensa no ser visto ( ab aliis non uideri... se uideri non arbitratur [A]); en relación con Dios en términos de objetividad: lo ve (tanto uidet patientius... [A']). Por último, el paralelismo entre los dos miembros exteriores tiene otro fundamento: ambos hablan de la ilusión del monje de no ser visto y hacen ver que se trata de una ilusión, con la diferencia de que en el primero la ilusión la trunca el hombre (uidetur... a quibus se uidetur non arbitratur [A]), y en el segundo Dios (tanto uidet sapientius... [A'] ${ }^{14}$.

Todo lo dicho se puede visualizar en esta presentación:

${ }^{14}$ Otras figuras retóricas presentes son la sinonimia: uidere/non latere; el homoteleuton: arbitratur/videatur; patientius/sapientius; el poliptoton:putare/putandus; uideri/uidetur/uideri, y uideri/uidet. Cabe señalar también el cambio de voz del verbo: la pasiva del primer miembro de la primera secuencia (A): uideri/videtur/uideri, se vuelve activa el segundo miembro de la segunda secuencia (A'): uidere/videt. 


$\begin{array}{lll}\text { conocimiento } & \text { A xxxxxxxxxxx A } & \begin{array}{l}\text { subjetividad ilusión truncada } \\ \text { hombre }\end{array} \\ \text { ocultamiento } & \text { B xxxxxxxxxxx B } & \\ \text { ocultamiento } & \text { B' } x \operatorname{xxxxxxx\quad B} & \end{array}$

conocimiento A' $\quad \begin{array}{ll}\text { Dios } \\ \text { objetividad ilusión truncada }\end{array}$

El legislador entra en la mente del monje que ha quebrantado la virtud de la castidad con su mirada lujuriosa para descubrir la causa psicológica que le lleva a comportarse de esa manera. Y la descubre en la convicción de que su acción quedará oculta, pues cree que no tendrá testigos. De inmediato le muestra que esa convicción es infundada, ya en el simple plano humano. Pero, habida cuenta de que está hablando a monjes, eleva el plano e introduce en la escena a Dios como testigo. Lo que quizá se pueda ocultar al hombre es imposible ocultarlo a la omnisciencia de Dios. Así el monje queda sin argumento para seguir con su conducta inmoral. El problema adquiere otra dimensión desde el momento que el testigo de su acto no es un cualquiera sino el que constituye la razón de su vida monástica, Dios. El legislador no sólo le ha derribado su muralla de seguridad; al dejarle desnudo ante Él, le ha desnudado también ante sí mismo, mostrando su farsa e hipocresía. Cierto, el trasgresor todavía puede defenderse y pensar: sí, Dios me ve, pero no da importancia al hecho. Estaríamos de nuevo ante el razonamiento ya visto en un quiasmo anterior: si el alma está pura, poco importa lo que vean los ojos. Pero el argumento queda desbaratado luego: Dios es tanto más paciente cuando más sabio. Por ello sería un error interpretar la paciencia como aprobación o consentimiento.

El texto nos permite hacer dos consideraciones que propiamente no representan ninguna novedad. La primera que el legislador ubica en los miembros exteriores lo positivo, lo que afirma: que la acción es vista, y en los interiores, lo negativo, lo que se niega: que la acción quede oculta. Aunque la negación que acompaña al verbo latere, lo convierta en sinónimo del uidere, queda en pie la diferencia entre la presentación positiva y la negativa, y la preferencia dada a la primera. La segunda consideración se centra sólo en los miembros exteriores. De nuevo el paso de uno a otro va de menos a más, en este caso de lo negativo a lo positivo: el primero contiene lo que no debe pensar el monje trasgresor (nec putare debet), y el segundo lo que debe pensar (putandus est), y del hombre a Dios: en el primer miembro el sujeto del pensar es el monje, en el segundo -aunque como sujeto pasivo- es Dios. De esta manera, el legislador muestra al monje que en él el error moral va acompañado de otro intelectual, esto es, una concepción 
equivocada de Dios. La imagen de Dios que subyace al pensamiento del monje es la de un Dios privado de algunos de sus atributos: la omnisciencia, la paciencia y la sabiduría.

\section{Quiasmo no 13 (par. 26)}

Magis quippe innocentes non estis, si fratres uestros, (A) quos indicando corrigere potestis,

(B) tacendo perire permittitis.

(B') Si enim frater tuus uulnus haberet in corpore quod uellet occultare, cum timet sanari, nonne crudeliter abs te sileretur $\mathrm{A}^{\prime}$ ) et misericorditer indicaretur?

El presente texto no deja duda de su estructura quiásmica como lo muestra el paralelismo de los miembros exteriores e interiores y su disposición invertida. En los primeros el paralelismo lo funda el verbo indicare: en gerundio (indicando [A]) y en forma personal (indicaretur [ $\left.\mathrm{A}^{\prime}\right]$ ); en los miembros interiores dos verbos sinónimos: callar (tacendo [B]) y silenciar (sileretur [B]).

El quiasmo contrapone en disposición especular una acción y una omisión. La acción -dar a conocer una falta- la expresan los miembros exteriores: los testigos han de darla a conocer (indicando [A]/indicaretur [ $\left[\mathrm{A}^{\prime}\right]$ ); la omisión -silenciar la falta-, los miembros interiores: los testigos no han de callar (tacere [B]/silere [B'].

Pero las dos secuencias no sólo contraponen en forma invertida las dos acciones que acabamos de señalar. Contraponen también, en simple paralelismo, los efectos de una y otra en la primera -plano objetivo- y su aspecto psicológico -plano subjetivo- en la segunda. En efecto, la primera secuencia presenta el efecto objetivo y positivo de la acción: la enmienda (corrigere [A]) y el negativo, también objetivo, de la omisión (perire [B]); la segunda, el aspecto subjetivo y negativo de la omisión: mostrarse cruel (crudeliter [B']), y.el aspecto subjetivo y positivo de la acción: mostrarse misericordioso (misericorditer [A'])

Anotamos también la disposición invertida en que aparecen, de una parte, las acciones $\mathrm{y}$, de otra, los efectos/aspectos: al indicando corrigere [A] y al tacendo perire [B] corresponde el crudeliter sileretur [B'], y el misericorditer indicaretur $\left[\mathrm{A}^{\prime}\right]^{15}$.

\footnotetext{
15 Señalamos además la figura del homeoteleuton por partida triple en los dos primeros miembros: indicando/tacendo; corrigere/perire/; potestis/permititis, y por partida doble en
} 
Lo dicho se puede visualizar en esta presentación:
acción
A $x x x x x x x x x x A$
positivo
omisión
B $\operatorname{xxxxxxxxxx\quad B}$
objetividad/efecto
omisión

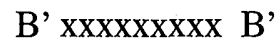
negativo
negativo
subjetividad/aspecto
acción
A $\operatorname{xxxxxxxxxx} A^{\prime}$
positivo

El mensaje principal del legislador es una invitación a la acción que, en el caso concreto, consiste en delatar, solo en determinadas circunstancias, al monje que, descubierto en su mirada lujuriosa, tras haber sido amonestado fraternamente, lejos de corregirse, sigue en sus trece. Una invitación formulada en términos positivos: dar a conocer la falta en determinadas circunstancias, y en términos negativos: no guardar silencio al respecto. Una vez más, el legislador presenta en los miembros exteriores lo que promueve, en este caso delatar al culpable, y en los miembros interiores lo que rechaza, en este caso, guardar silencio sobre su falta.

La razón de su mandato es doble y aparece en cada una de las secuencias. El legislador se coloca, en la primera, en el ámbito objetivo moral-espiritual. El paralelismo entre sus dos miembros ofrece puntos para la reflexión. Primero: a la acción física de uno (hablar o callar) corresponde una "pasión" en el otro (perecer o no perecer moralmente). Al valor positivo de la acción de delatar, que procede del deseo de que se enmiende el culpable, no de la voluntad de perjudicarle, añade el efecto negativo del callar: el hecho funesto de la muerte (moral) del acusado: no un mal insignificante, sino el mal supremo, el perecer. El monje que calla y con su silencio no impulsa la enmienda del culpable se hace responsable de la muerte que este acabará sufriendo. Para que no tenga escapatoria, el legislador añade que su responsabilidad no es por acción, sino por omisión; ciertamente no le da muerte en acción directa, pero permite (permittitis) que muera. Antes quizá les podía disculpar una eventual ignorancia; ahora ya no, porque el legislador lo ha dejado bien claro: "podéis (potestis) hacer que se enmiende". Como la imposibilidad de evitar un mal, propio o ajeno, exime de responsabilidad, así la posibilidad de evitarlo hace responsable a quien no lo evita.

los dos últimos del quiasmo: crudeliter/misericorditer; sileretur/indicaretur; la combinación de la anáfora y epífora: un homeoteleuton (indicando/tacendo) abre los dos miembros de la primera secuencia (A-B) y otro (sileretur/indicaretur) cierra los dos de la segunda secuencia (B'-A'). 
El legislador introduce un ejemplo tomado del ámbito físico -referido a la familia natural-con el que probar la bondad de un modo de actuar semejante en el ámbito moral-espiritual -referido a la familia espiritual-. El valor del ejemplo aducido le viene de proceder del ámbito de la familia natural y del ámbito de la salud física. Este último aspecto sirve al legislador para poner a los monjes ante sí mismos y ante la propia jerarquía de valores. El no estar dispuestos a aceptar en el ámbito de la salud moral-espiritual lo que estarían dispuestos a aceptar en el ámbito de la salud física habían de verlo como indicador inequívoco de cómo, por mucho que viviesen el monasterio, aún no habían levantado el vuelo hacia bienes superiores. En esta misma dirección apunta el otro aspecto indicado. La base de la reflexión es la misma: no estar dispuestos a hacer por quien mora con ellos en el monasterio lo que estarían dispuestos a hacer por un hermano carnal habían de verlo también como indicador de que no lo consideran hermano y de que, por tanto, todavía no han entrado a formar parte de la nueva familia. En el cambio del número, en el paso del plural (potestis/permititis), al singular (frater tuus, abs te sileretur) cabe ver la voluntad del legislador de mostrar la concreción de la fraternidad monástica en aquel que se tiene al lado y sobre todo si sufre un mal. Fraternidades en abstracto no le sirven.

Una vez aducidas las razones morales objetivas, el legislador aduce otras de carácter psicológico, referidas al ámbito de los sentimientos. La crueldad y la misericordia son dos sentimientos opuestos, valorado negativamente el primero y positivamente el segundo por la sociedad en conjunto y por las personas concretas. Toda persona quiere ser objeto de misericordia antes que de crueldad y, de igual manera, la persona sana y noble se siente mejor practicando la misericordia que mostrándose cruel. Ante esta experiencia, lo que ha hecho el legislador ha sido unir el sentimiento alabado -la misericordia- a la acción que recomienda -el hablar- y el sentimiento reprochado -la crueldad - a la que reprocha -el callar-.

Los dos miembros sueltos que coronan la estructura quiásmica tienen también su mensaje. Si el callar tiene como consecuencia la muerte del hermano, es porque el hermano estaba ya enfermo. Su interior (in corde) ya estaba infectado de una podredumbre que, por su propio dinamismo, tiende a invadirlo todo. El legislador ha tomado el mal físico como ejemplo del mal moral. Al usarlo, quiere advertir también de la fuerza expansiva de la lujuria, el mal de que está hablando. En esta situación el primer paso para eliminarlo es darlo a conocer; en consecuencia el que calla permite su desarrollo hasta producir la muerte. 


\section{Quiasmo no 14 (par. 27.29)}

(A) Conuictus uero, secundum praepositi,

(B) uel etiam presbyteri...

(C) arbitrium debet emendatoriam subire uindictam...

(C') si ... deprehenditur atque conuincitur secundum arbitrium

(B') presbyteri

(A') vel praepositi gravius enmendetur.

El presente texto en sí mismo considerado es otro modelo de estructura concéntrica. Cada una de sus dos secuencias consta de tres miembros dispuestos en forma especular, propia del quiasmo.

$\mathrm{La}$ estructura quiásmica resulta clara del paralelismo e inversión de los tres miembros de cada secuencia. El paralelismo de los miembros exteriores, se funda en la mención en ambos del prepósito (praepositi [A-A']); el paralelismo de los miembros interiores (B-B'), en la mención en ambos del presbítero (praesbyteri [B-B']), y el de los términos céntricos en la mención del criterio (arbitrium [C y $\left.\left.\mathrm{C}^{\prime}\right)\right]$ ).

La estructura quiásmica contrapone especularmente dos autoridades que coexisten en el monasterio con su respectivo criterio. Los miembros exteriores se refieren al prepósito (praepositi [A-A']); los miembros interiores, al presbítero (praesbyteri [B-B']) y los miembros céntricos, sus respectivos criterios (arbitrium [C-C']).

Aunque no aparece en el texto trascrito, ambas secuencias tienen en el trasfondo pecados contra la castidad, con la diferencia de que en la primera se trata de pecados cometidos mediante el sentido de la vista (oculi petulantia [A-B-C]), y en el segundo, de los restantes pecados (ceteris ... peccatis [ $\left.\left.\mathrm{C}^{\prime}-\mathrm{B}^{\prime}-\mathrm{A}^{\prime}\right]\right)$; con la diferencia también de que en el primer caso se trata de la primera manifestación del pecado (coepta) y en el segundo de un pecado ya afirmado (progressus fuerit) ${ }^{16}$.

A diferencia de la anterior, en esta estructura los miembros concéntricos expresan el núcleo de la voluntad del legislador: que las trasgresiones contra la castidad sean sancionadas sean por el prepósito, sea por el presbítero, según sus criterios específicos (arbitrium).

Lo dicho se puede visualizar en esta presentación:

${ }^{16}$ Otras figuras retóricas son la anáfora (secundum/secumdum) , I homeoteleuton en la conclusión de los términos extremos y medios (praepositi/presbyteri; $;$ resbyteri/praepositi) y la epanadiplosis en los miembros céntricos (arbitrium.../arbitrium). 


\begin{tabular}{|c|c|c|}
\hline autoridad (a)/prepósito & A $x x x x x x x x x x A$ & pecados (a) \\
\hline autoridad (b)/presbítero & B xxxxxxxxxx B & \\
\hline & 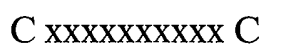 & criterio (1) \\
\hline & $C^{\prime} \operatorname{xxxxxxxxx} C^{\prime}$ & criterio (2) \\
\hline autoridad (b')/presbítero & B' $x x x x x x x x x$ B' & pecados (a') \\
\hline autoridad (a')/prepósito & $A^{\prime} \operatorname{xxxxxxxxx} A^{\prime}$ & \\
\hline
\end{tabular}

Mirando esta representación gráfica se advierten dos cosas simultáneamente. Primero, que la comunidad monástica destinataria del Praeceptum tenía como dos cabezas; una, el prepósito y otra, el presbítero; luego, que los miembros exteriores los ocupa el prepósito, y los miembros interiores, el presbítero. El primero, el prepósito, representa la autoridad específicamente monástica; el segundo, el presbítero representa la autoridad eclesial. Si el legislador actúa de esa manera es porque se considera un legislador monástico. La cabeza del monasterio en cuanto tal es el prepósito, no el presbítero, aunque este tenga también su función en relación con los monjes, pero no ya en cuanto monjes, sino en cuanto cristianos.

$\mathrm{Si}$ el legislador introduce en este momento al prepósito y al presbítero se debe a la potestad sancionadora de ambos en pecados referidos al ámbito de la lujuria. En este aspecto, el legislador contempla que ambos pueden actuar, en principio, sobre los mismos pecados; tanto sobre aquellos en que el vicio comienza a manifestarse (a), como sobre aquellos que muestran que ha avanzado ( $\left(a^{\prime}\right)$. Pero una y otra autoridad no aparecen aquí jerarquizadas entre sí $^{17}$. Lo que las distingue es el ámbito de sus respectivas actuaciones: el de la disciplina regular y el de la vida de la gracia. Por eso, según la naturaleza de la falta que haya que sancionar, puede intervenir uno $u$ otro o incluso los dos (uel etiam). Por supuesto, al hablar del criterio (arbitrium) del prepósito y del presbítero, el legislador no piensa en el juicio estrictamente personal de quien en un momento determinado desempeña la función de prepósito o de presbítero, sino en el juicio fundado en los valores que representan, los específicamente monásticos o los comunes a todo cristiano.

La imbricación de los distintos quiasmos del capítulo se puede ver en esta disposición gráfica:

17 Esa jerarquización sí aparece en el capítulo séptimo en que el legislador considera que los monjes deben obedecer aún más al presbítero que al prepósito y que este tiene mayor rango que aquel (multo magis presbytero/ cuius est apud uos maior auctoritas). 
(a) Neque enim quando proceditis feminas uidere prohibemini, sed appetere,

(b) aut ab ipsis appeti velle, criminosum est.

(b') Nec solo tactu ... sed aspectu quoque appetitur (concupiscentia feminarum)

(a') et appetit concupiscentia feminarum...

(A) Nec solo tactu et affectu,

(B) sed aspectu quoque appetitur et appetit concupiscentia feminarum...

(a) Nec dicatis uos habere animos pudicos

(b) si habetis oculos impudicos

(b') quia impudicus oculus

(a') impudici cordis est nuntius.

(a) Nec putare debet qui in feminam figit oculum... ab aliis non uideri, cum hoc facit; uidetur omnino et a quibus se uideri non arbitratur.

(b) Sed ecce lateat et a nemine hominum uideatur,

(b') quid faciet de illo desuper inspectore quem latere nihil potest?

(a') An ideo putandus est non uidere, quia tanto videt patientius, quanto sapientius?

(B') si hanc de qua loquor oculi petulantiam...

Magis quippe innocentes non estis, si fratres uestros,

(a) quos indicando corrigere potestis,

(b) tacendo perire permittitis.

(b') Si enim frater tuus uulnus haberet in corpore quod uellet occultare, cum timet sanari, nonne crudeliter $a b$ s te sileretur

(a') et misericorditer indicaretur?

(a) Conuictus uero, secundum praepositi,

(b) uel etiam presbyteri...

(c) arbitrium debet emendatoriam subire uindictam...

(A') etiam in ceteris inueniendis...peccatis...

(c') si ... deprehenditur atque conuincitur secundum arbitrium (b') presbyteri

(a') vel praepositi gravius enmendetur. 
